\title{
An individual placement and support programme is more effective than skills training and temporary employment for people with severe mental illness
}

Mueser KT, Clark RE, Haines M, et al. The Hartford study of supported employment for persons with severe mental illness. J Consult Clin Psychol 2004;72:479-90.

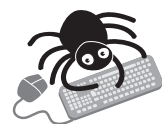

This article

contains extra text on the EBMH website

\section{How does individual placement and support compare with a psychosocial rehabilitation programme or standard} services for vocational rehabilitation in people with severe mental illness?

\section{METHODS}

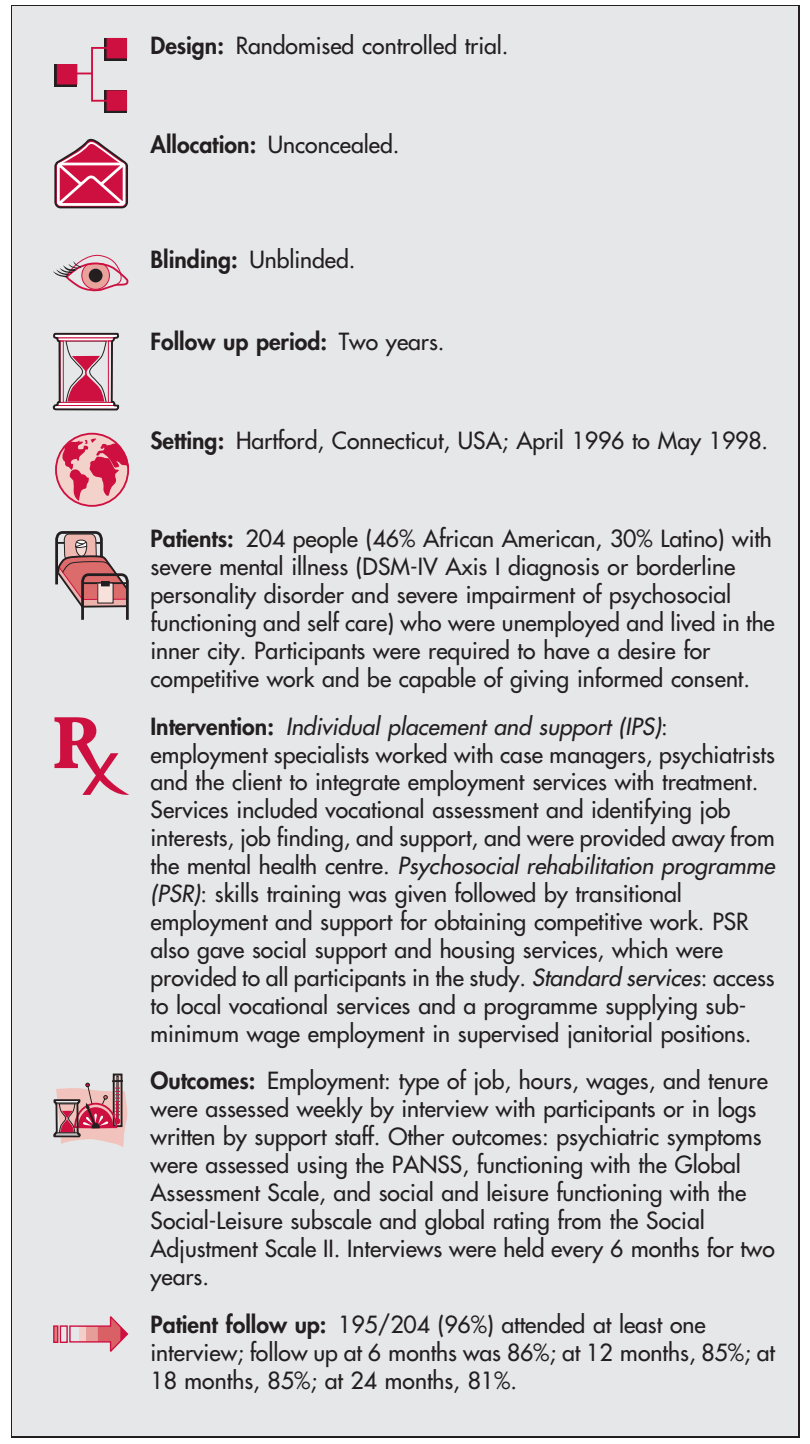

For correspondence: Kim T Mueser, New Hampshire-Dartmouth Psychiatric Research Center, Main Building, 105 Pleasant Street, Concord, NH 03301, USA; kim.t.mueser@dartmouth.edu

Sources of funding: US Department of Health and Human Services (DHHS), Substance Abuse and Mental Health Services Administration (SAMHSA), Center for Mental Health Services (CMHS), National Institute of Mental Health (NIMH).

\section{MAIN RESULTS}

At two years, IPS significantly improved employment outcomes compared with PSR or standard services (see http://www. ebmentalhealth.com/supplemental for table). There were no significant differences among groups for the other outcomes.

\section{CONCLUSIONS}

Individual placement and support is more effective for finding competitive employment for people with serious mental illness than psychosocial rehabilitation or standard services.

\section{Commentary}

7 he Hartford study confirms that factors such as integrated support services, rapid job placement, and matching individuals with specific job preferences-as purported by the individual placement and support (IPS) model-cannot predict long term job sustainability (tenure over six months) for people with mental illnesses. Judith Cook reported similar findings for job retention for individuals participating in a non-IPS model vocational programme. To determine the constellation of significant factors that can lead to longer retention, programmes that exceed the job retention rate of six months for supported employment placements should be examined, as in the Chinook clubhouse study. ${ }^{2}$

The Hartford study was unique in the comparison of three different vocational rehabilitation approaches within the same geographical region. However, to suggest that one model is preferred over another as a general recommendation negates consumer choice and discounts individual needs and preferences. The IPS model may be more suited to certain individuals, such as those from Latino populations or individuals who prefer more intensive, individualised settings. Others may benefit from participating in a clubhouse where one becomes part of a community that offers an array of support including employment, education, housing, and social opportunities.

Findings in the Hartford study would have been more relevant if an IPS model had been compared to an International Center for Clubhouse Development (ICCD) certified clubhouse. Although the psychosocial rehabilitation (PSR) programme in the paper was similar to other PSR programmes in Connecticut, it is unclear whether this PSR programme would have met the criteria in the clubhouse fidelity scale. ${ }^{3}$ There seems to be an inherent misunderstanding in this study, and in psychiatric rehabilitation literature in general, with respect to the clubhouse model and transitional, supported, and independent employment. ${ }^{4}$ The authors acknowledge more research in this area is necessary. Studies that examine outcomes of existing service programmes that have not been researched extensively may prove beneficial.

JoAnn Dorio

Chinook Clubhouse, a program of the Mental Health Center of Boulder County, Boulder, CO, USA

1 Cook JA. Job ending among youth and adults with severe mental illness. J Ment Health Adm 1992;19:158-69.

2 Dorio J. Tying it all together the PASS to success: a comprehensive look at promoting job retention for workers with psychiatric disabilities in a supported employment program. Psychiatr Rehabil J 2004:28:32-9.

3 Wang Q, Macias C, Jackson R. First step in the development of a clubhouse fidelity instrument: content analysis of clubhouse certification reports. Psychiatr Rehabil J 1999;22:294-8.

4 McKay C, Johnsen M, Stein R. Employment outcomes in Massachusetts clubhouses. Psychiatr Rehabil J 2005 (in press). 